\title{
A Randomized, Double-Blind, Placebo- and Active-Controlled, Escalating Single-Dose Study to Evaluate the Safety, Tolerability, Pharmacokinetic, and Pharmacodynamic Profiles of Subcutaneous Eflapegrastim in Healthy Japanese and Caucasian Subjects
}

\author{
Yoomin Jeon $^{1,2,4}$ (D) Nora Lee $^{5}$ (D) Seungjae Baek ${ }^{5} \cdot$ JaeDuk Choi $^{5} \cdot$ Stanford Jhee $^{6}$ (D) Howard Lee Hew, $^{1,3,4,7}$ (D)
}

Accepted: 13 December 2021 / Published online: 6 January 2022

(c) The Author(s) 2022

\begin{abstract}
Background Eflapegrastim (Rolontis ${ }^{\circledR}$ ) is a novel long-acting pegylated recombinant human granulocyte colony-stimulating factor (G-CSF). Eflapegrastim has been developed to reduce the duration and incidence of chemotherapy-induced neutropenia in cancer patients using patient-friendly, less-frequent administration.

Objective This phase I study aimed to evaluate the safety, tolerability, pharmacokinetic (PK), pharmacodynamic (PD), and immunogenicity of eflapegrastim following a single subcutaneous administration to healthy Japanese and Caucasian subjects. Methods A randomized, double-blind, placebo- and active-controlled, dose-escalation study was conducted in healthy Japanese and Caucasian subjects. Eligible subjects randomly received a single subcutaneous administration of eflapegrastim (1.1, $3.3,10,45,135$, and $270 \mu \mathrm{g} / \mathrm{kg}$ ), pegfilgrastim $6 \mathrm{mg}$, or placebo in a ratio of 6:2:2 (Cohorts 1-2, Caucasian subjects only) or 12:2:2 (Cohorts 3-6, Japanese and Caucasian subjects). Safety and tolerability were assessed throughout the study. Serial blood samples were collected predose and up to day 22 postdose for PK and PD analyses. PK assessments were performed in the 45,135 , and $270 \mu \mathrm{g} / \mathrm{kg}$ dose groups. Antidrug antibodies to eflapegrastim were determined at baseline up to day 42 after the first dose for immunogenicity.

Results A total of 84 subjects ( 42 males and 42 females) were enrolled, and 78 (31 Japanese and 47 Caucasian subjects) completed the study as planned. Japanese and Caucasian subjects showed similar PK and PD profiles. In the 45, 135, and $270 \mu \mathrm{g} / \mathrm{kg}$ dose groups, the maximum serum concentration $\left(C_{\max }\right)$ of eflapegrastim exhibited a dose-proportional increase, whereas its exposure increased greater than dose proportional in both ethnic groups. The mean area under the effect-time curve $\left(\mathrm{AUEC}_{\text {last }}\right)$ and maximum serum concentration of both absolute neutrophil count $\left(\mathrm{ANC}_{\max }\right)$ and $\mathrm{CD} 34^{+}$cell count $\left(\mathrm{CD} 34^{+}{ }_{\text {max }}\right)$ increased in a dose-dependent manner. There were no significant adverse events attributable to eflapegrastim or pegfilgrastim in both Japanese and Caucasian subjects. No neutralizing antibodies against G-CSF were detected.

Conclusions Eflapegrastim was safe and well tolerated at doses up to $270 \mu \mathrm{g} / \mathrm{kg}$ in healthy Japanese and Caucasian subjects. In both ethnic groups, eflapegrastim showed dose-dependent PK and the exposure to eflapegrastim was positively correlated with ANC and $\mathrm{CD}_{3} 4^{+}$cell count. The comparable PK and PD profiles of eflapegrastim in Japanese and Caucasian subjects may indicate the same dosage regimen is acceptable.
\end{abstract}

Clinical Trial Registration ClinicalTrials.gov: NCT01037543 (23 December 2009).

\section{Introduction}

Yoomin Jeon and Nora Lee contributed equally to this work.

Howard Lee

howardlee@snu.ac.kr

Extended author information available on the last page of the article
Neutropenia, a common complication of chemotherapy, is characterized by an abnormally low concentration of absolute neutrophil count (ANC), which may lead to hospitalization and increase the risk of infection [1]. Patients with neutropenia may have to delay, reduce, or discontinue their 


\section{Key Points}

In this phase I study, eflapegrastim (Rolontis ${ }^{\circledR}$ ), a novel long-acting granulocyte colony-stimulating factor developed to prevent chemotherapy-induced neutropenia, was evaluated in healthy Japanese and Caucasian subjects.

A single subcutaneous administration of eflapegrastim $1.1-270 \mu \mathrm{g} / \mathrm{kg}$ was safe and well tolerated in Japanese and Caucasian subjects.

The Japanese and Caucasian subjects showed similar pharmacokinetic and pharmacodynamic profiles of eflapegrastim $45-135 \mu \mathrm{g} / \mathrm{kg}$, suggesting that different dosage regimens based on ethnicity may not be required.

chemotherapy, which harbors potential negative clinical outcomes [1]. To minimize the aforementioned risk, physicians have widely prescribed the recombinant human (rh) granulocyte colony-stimulating factor (G-CSF) since 1991 [2, 3]. $\mathrm{G}-\mathrm{CSF}$ is a glycoprotein that stimulates the bone marrow to produce granulocytes and stem cells and release them into the bloodstream [4].

Filgrastim (Neupogen ${ }^{\circledR}$ ), an rh-G-CSF, requires multiple daily injections due to its short half-life $(3.5 \mathrm{~h})$ in humans [5]. To overcome the inconvenience of multiple daily injections, pegfilgrastim (Neulasta ${ }^{\circledR}$ ), a long-acting rh-G-CSF conjugated with polyethylene glycol (PEG), was developed to extend the half-life of filgrastim, and thereby more convenient and less frequent administration per chemotherapy cycle [6]. The current guidelines by both the National Comprehensive Cancer Network [7] and the American Society of Clinical Oncology [8] recommend pegfilgrastim be administered the day after or up to 4 days following chemotherapy, but not on the same day of chemotherapy to prevent enhanced chemotherapy-induced neutropenia due to the proliferation of myeloid progenitor cells by pegfilgrastim [9].

Eflapegrastim (Rolontis ${ }^{\circledR}$ ) or HM10460A, a novel longacting rh-G-CSF, conjugates the G-CSF analog (the 17th serine-G-CSF) and the N-terminus of an rh-immunoglobulin (Ig) G4 Fc fragment (HMC001) via a $3.4 \mathrm{kDa}$ PEG linker [10] using Hanmi's proprietary long-acting protein/peptide discovery technology (LAPSCOVERYTM). The LAPSCOVERY ${ }^{\mathrm{TM}}$ technology enables eflapegrastim to be longacting by increasing its uptake into the bone marrow [11] while decreasing the renal clearance. Eflapegrastim showed not only similar in vitro binding affinity to that of pegfilgrastim [12] but also greater potency than pegfilgrastim in chemotherapy-induced neutropenic rats [13]. Moreover, the greater bone marrow uptake and retention of eflapegrastim was shown to reduce the duration of neutropenia compared with pegfilgrastim, and hence supporting the potential for same-day dosing of eflapegrastim with chemotherapy [12]. In healthy Korean subjects, a single subcutaneous administration of eflapegrastim showed a greater than dose-proportional increase in exposure, while both the ANC and CD34 ${ }^{+}$ cell count were positively correlated with the area under the concentration-time curve (AUC) [10].

This first-in-human study of eflapegrastim was conducted to evaluate the potential ethnic differences between Japanese and Caucasian subjects. The primary objective was to evaluate the safety and tolerability of eflapegrastim after a single subcutaneous administration in healthy Japanese and Caucasian subjects. The secondary objectives were to (1) assess the pharmacokinetic (PK) and pharmacodynamic (PD) profiles, and immunogenicity of a single subcutaneous administration of eflapegrastim, and (2) characterize the $\mathrm{PK} / \mathrm{PD}$ relationship in those subjects.

\section{Methods}

\subsection{Subjects and Study Design}

Males and females aged 20-45 years, with a body mass index (BMI) of $18.0-29.9 \mathrm{~kg} / \mathrm{m}^{2}$ were eligible for this study if they were healthy by medical history, physical examination, vital signs, 12-lead electrocardiogram (ECG), and laboratory test (chemistry, hematology, and urinalysis) assessments. Subjects were defined as Japanese if they were born in Japan, had two parents of Japanese descent, held a Japanese passport, and had not lived outside Japan for $>5$ years, while subjects were defined as Caucasian if they were of European or Latin American descent. Subjects were excluded if they had previously received G-CSF-related products. Subjects with a history or presence of a significant disease, a positive urine drug/alcohol screening test or a drug/alcohol abuse history, or a positive test for hepatitis $\mathrm{B}$, hepatitis $\mathrm{C}$, or human immunodeficiency virus were also excluded. Prescription or nonprescription drugs within 14 or 7 days, respectively, prior to administration of the study drug were not allowed. Pregnant or breastfeeding subjects were not eligible for this study.

This was a first-in-human, randomized, double-blind, placebo- and active-controlled, single-dose, phase I study to evaluate the safety, tolerability, PK, PD, and immunogenicity of eflapegrastim in healthy Japanese and Caucasian subjects. The study consisted of six cohorts, in which subjects randomly received a single subcutaneous administration of eflapegrastim, pegfilgrastim $6 \mathrm{mg}$, or placebo in a ratio of 6:2:2 (Cohorts 1 and 2) or 12:2:2 (Cohorts 3-6). The dose of eflapegrastim in Cohorts $1-6$ was 1.1, 3.3, 10, 45, 135, and $270 \mu \mathrm{g} / \mathrm{kg}$, respectively. No Japanese subjects were enrolled into the two lowest dose groups (Cohorts 1 and 2), whereas 
both Japanese and Caucasian subjects were recruited into Cohorts 3-6 in the same ratio, or 8:8. Additionally, the same number of males and females were enrolled in each cohort.

The No Observed Adverse Effect Levels (NOAEL) assessed from the preclinical toxicity studies in rats and monkeys were 0.161 and $0.969 \mathrm{mg} / \mathrm{kg}$, respectively. In order to ensure the safety of eflapegrastim, the maximum recommended starting dose of eflapegrastim in humans was estimated to be $1.1 \mu \mathrm{g} / \mathrm{kg}$ after applying a standard safety factor of 10 . Six ascending dose cohorts were planned with a maximum planned dose of $270 \mu \mathrm{g} / \mathrm{kg}$.

This study was conducted at the Early Phase Clinical Unit of PAREXEL International (Glendale, CA, USA). The clinical study protocol, any amendments, subject information sheets, written informed consent forms, and relevant study documentation were reviewed and approved by the Institutional Review Board (Aspire IRB; ClinicalTrials.gov registration number NCT01037543). The study was conducted in full compliance with the International Conference on Harmonization (ICH) Good Clinical Practice guidelines and the Declaration of Helsinki. All subjects provided written informed consent before study entry.

\subsection{Safety and Tolerability Assessments}

Safety was assessed at regular intervals throughout the entire study based on physical examinations, injection site assessments, splenic assessments by ultrasound, laboratory tests, 12-lead ECG, vital signs, immunogenicity assessment, and adverse event (AE) monitoring. Local tolerability was assessed based on the presence of inflammatory signs such as spontaneous pain or tenderness, erythema, swelling, and induration at 1,24 , and $48 \mathrm{~h}$ postdose. The end-of-study visit occurred on day 42 after a single dose of eflapegrastim.

A serious $\mathrm{AE}$ was defined as any undesirable experience occurring to a subject at any dose result in one of the following: death, life-threatening event, hospitalization (initial or prolonged), disability (significant or persistent), and congenital anomaly. The severity of all observed AEs was assessed based on a three-level scale of mild, moderate, and severe, respectively, an event that is easily tolerated and not interfering with daily activity, that interferes with daily activity, and that requires medical intervention.

\subsection{Bioanalysis}

The immunogenicity of eflapegrastim was assessed by a validated enzyme-linked immunosorbent assay (ELISA). The serum concentrations of eflapegrastim were determined using an anti-human G-CSF ELISA kit (Synexa Life Sciences, Cape Town, South Africa; reference number SG005/2010). The assay depended on the 96-well streptavidin-coated microplates, to which biotinylated eflapegrastim was added. Following incubation and washing step, the detection antibody (i.e., digoxigenin-labeled anti-human IgG4) was bound to eflapegrastim. After an additional incubation and washing step, an anti-digoxigenin peroxidaselabeled antibody was added with a further incubation step. A substrate was added, colorization was stopped, and the optical density of each well was measured at $450 \mathrm{~nm}$ using a microplate reader.

The serum concentrations of eflapegrastim were determined from the standard curve, which was constructed by plotting the blank-corrected mean optical density against the serum concentrations of eflapegrastim using a four-parameter logistic regression model. For the serum eflapegrastim analysis, the standard curve was accurate $(-6.55 \% \leq \%$ relative error $\leq 2.37 \%)$ and precise $(0.13 \% \leq \%$ coefficient of variation $\leq 13.3 \%$ ) over the calibration range of 3.13-200 $\mathrm{ng} / \mathrm{mL}$, with a lower limit of quantification (LLOQ) of 3.13 $\mathrm{ng} / \mathrm{mL}$.

Antidrug antibodies (ADA) to eflapegrastim, pegfilgrastim, placebo, and G-CSF were determined at screening and on days 15, 22, and 42 using ELISA. If any of the subjects in a dose group were positive or the immunogenicity results were positive, the dose was not escalated to the next higher level.

\subsection{Pharmacokinetic Assessment}

Blood samples were obtained to determine serum eflapegrastim and pegfilgrastim concentrations at $0,0.25,0.5$, $0.75,1,2,3,4,6,8,12,16,24,36$, and $48 \mathrm{~h}$ and on days 4 , $5,6,7,11,15$, and 22 . Individual PK parameters of eflapegrastim and pegfilgrastim were obtained by noncompartmental methods using the Phoenix WinNonlin software (Professional version 5.1; Pharsight Corporation, Mountain View, CA, USA). The maximum serum concentration $\left(C_{\max }\right)$ and time to reach $C_{\max }\left(T_{\max }\right)$ were acquired directly from the observed values. AUC from time zero to the last observed concentration $\left(\mathrm{AUC}_{\text {last }}\right)$ was calculated using the linear trapezoidal method. The terminal elimination half-life $\left(t_{1 / 2}\right)$ was $\ln (2)$ divided by the apparent terminal elimination rate constant $\left(\lambda_{z}\right)$, which was estimated by linear regression of the terminal linear portion of the log concentration versus time curve. The AUC from time zero to infinity $\left(\mathrm{AUC}_{\infty}\right)$ was the sum of $\mathrm{AUC}_{\text {last }}$ and $\mathrm{C}_{\text {last }} \lambda_{z}$, where $\mathrm{C}_{\text {last }}$ was the last observed concentration. The apparent clearance $(\mathrm{CL} / \mathrm{F})$ was the dose divided by $\mathrm{AUC}_{\infty}$.

\subsection{Pharmacodynamic Assessment}

PD endpoints included ANC and $\mathrm{CD} 34^{+}$cell count. Blood samples for ANC were collected at 0, 0.25, 0.5, 0.75, $1,2,3,4,6,8,12,16,24,36$, and $48 \mathrm{~h}$ postdose and on days $4,5,6,7,11,15$, and 22 . On the other hand, blood 
samples for $\mathrm{CD} 34^{+}$cell count were collected at predose, 24 and $48 \mathrm{~h}$ postdose and on days $4,5,6,7,11,15$, and 22. The maximum serum concentration of $\mathrm{ANC}\left(\mathrm{ANC}_{\max }\right)$ and $\mathrm{CD} 34^{+}$cell count $\left(\mathrm{CD} 34^{+}{ }_{\text {max }}\right)$ and time to reach peak ANC $\left(T_{\text {max_ANC }}\right)$ and $\mathrm{CD} 34^{+}$cell count $\left(T_{\text {max }_{-} \mathrm{CD} 34+}\right)$ were derived from the observed values. The mean area under the effect-time curve $\left(\mathrm{AUEC}_{\text {last }}\right.$ ) was calculated as the area under the PD response curve from time zero to the last observed value using the linear trapezoidal rule. For each of ANC and $\mathrm{CD} 34^{+}$cell count, the derived parameters were calculated using the Phoenix WinNonlin software (Professional version 5.1; Pharsight Corporation).

\subsection{Statistical Analysis}

Given the exploratory nature of this study, no formal sample size estimation was performed. However, a sample size of 84 subjects (10 subjects in Cohorts 1 and 2; 16 subjects in Cohorts 3-6) was considered adequate. The number of subjects experiencing AEs and the number of AEs were summarized by dose and ethnic group. Safety data, including laboratory tests, vital signs, and 12-lead ECG results, were summarized by dose and ethnic group using descriptive statistics for the actual value and for a mean change from baseline at each time point. The PK and PD parameters were summarized by dose and ethnic group using descriptive statistics. Within each ethnic group, dose proportionality of the PK parameters was evaluated using a power model, where log-transformed $\mathrm{AUC}_{\text {last }}, \mathrm{AUC}_{\infty}$, and $C_{\max }$ were regressed, respectively, with log-transformed dose. If the two-sided 95\% confidence interval (CI) for the slope included 1, dose proportionality for the corresponding PK parameter was concluded [14]. A $p$ value $<0.05$ was considered statistically significant. For PK/PD analysis, the relationship between serum concentrations of eflapegrastim (or pegfilgrastim) and ANC and $\mathrm{CD} 34^{+}$cell count, respectively, was evaluated using SAS PROC REG (version 9.1; SAS Institute Inc, Cary, NC, USA).

\section{Results}

\subsection{Subjects}

Of 84 subjects enrolled, 36 Japanese and 48 Caucasian subjects participated in the study and a total of 78 subjects

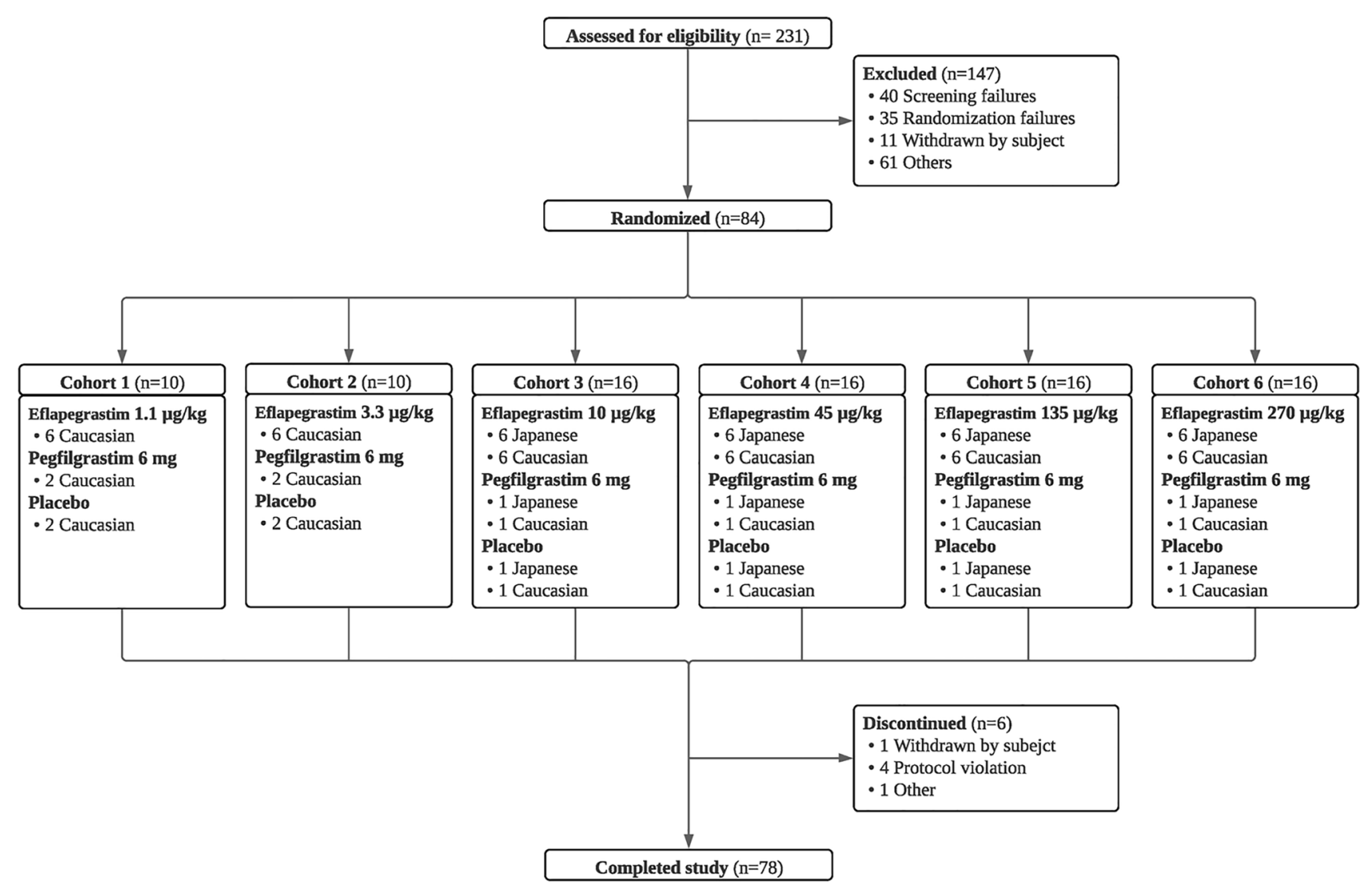

Fig. 1 Subject disposition. A total of 36 Japanese and 48 Caucasian subjects randomly received a single subcutaneous administration of eflapegrastim, pegfilgrastim, or placebo in a ratio of 6:2:2 (Cohorts 1 and 2) or 12:2:2 (Cohorts 3-6) 


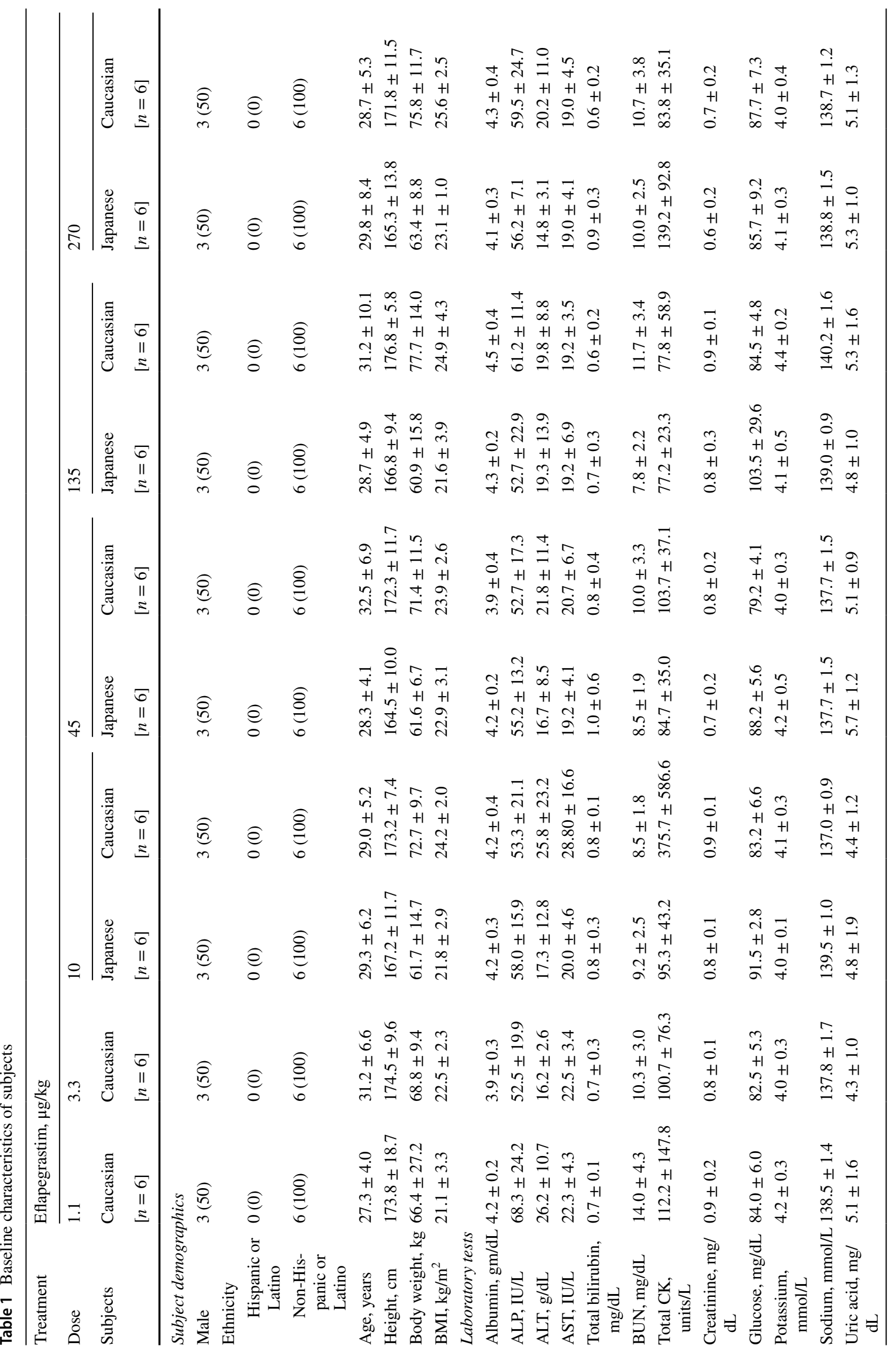




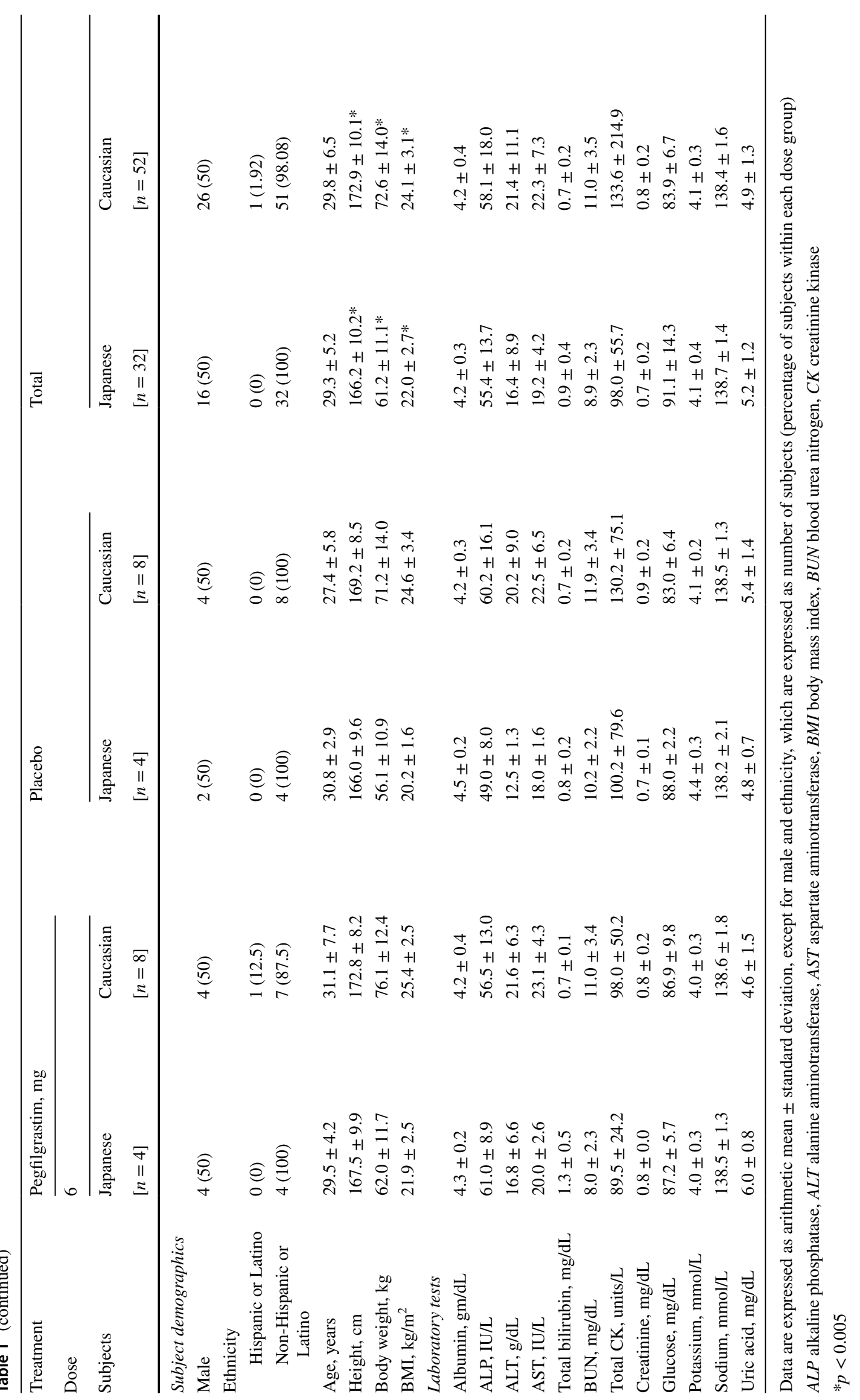




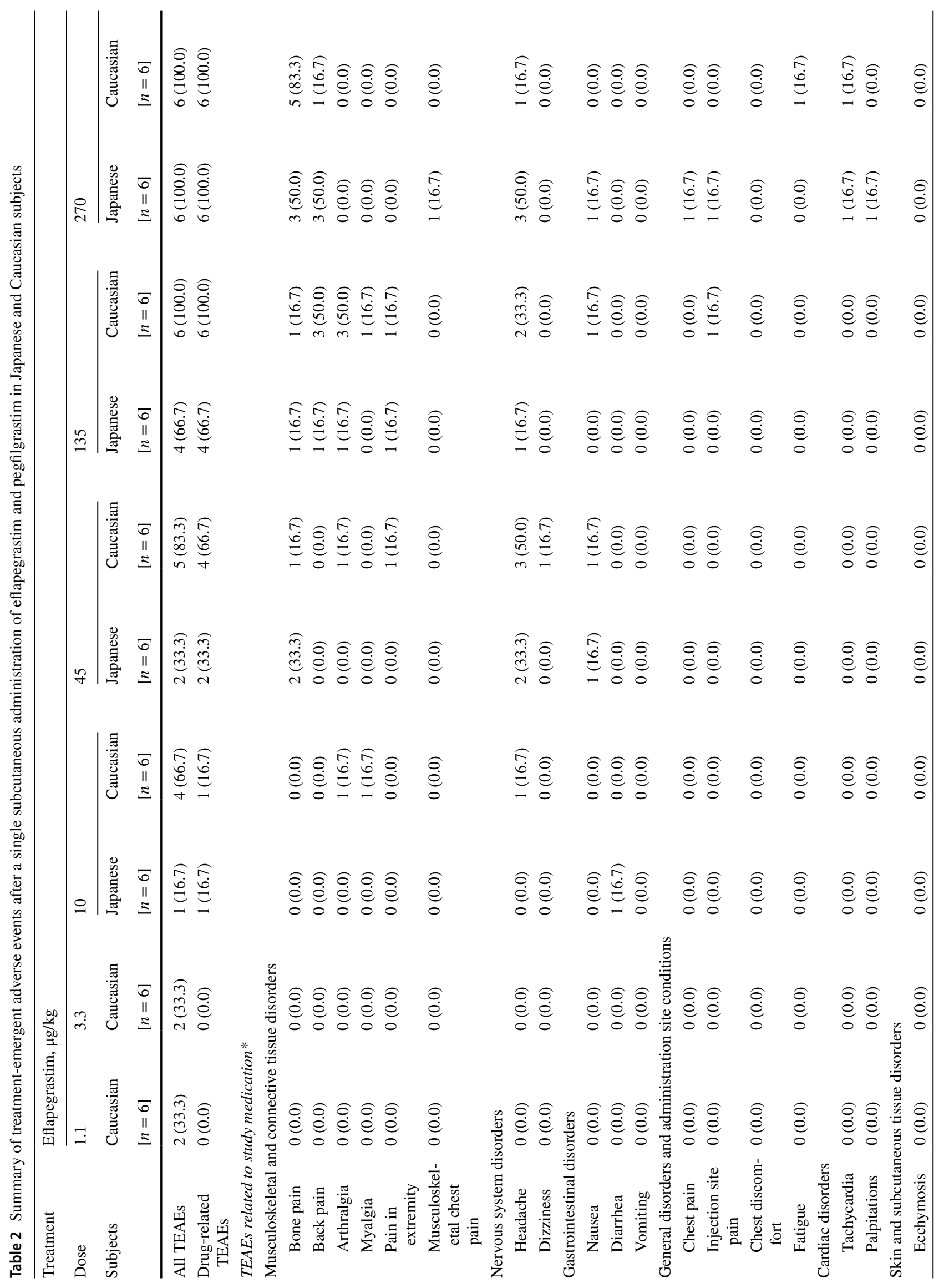




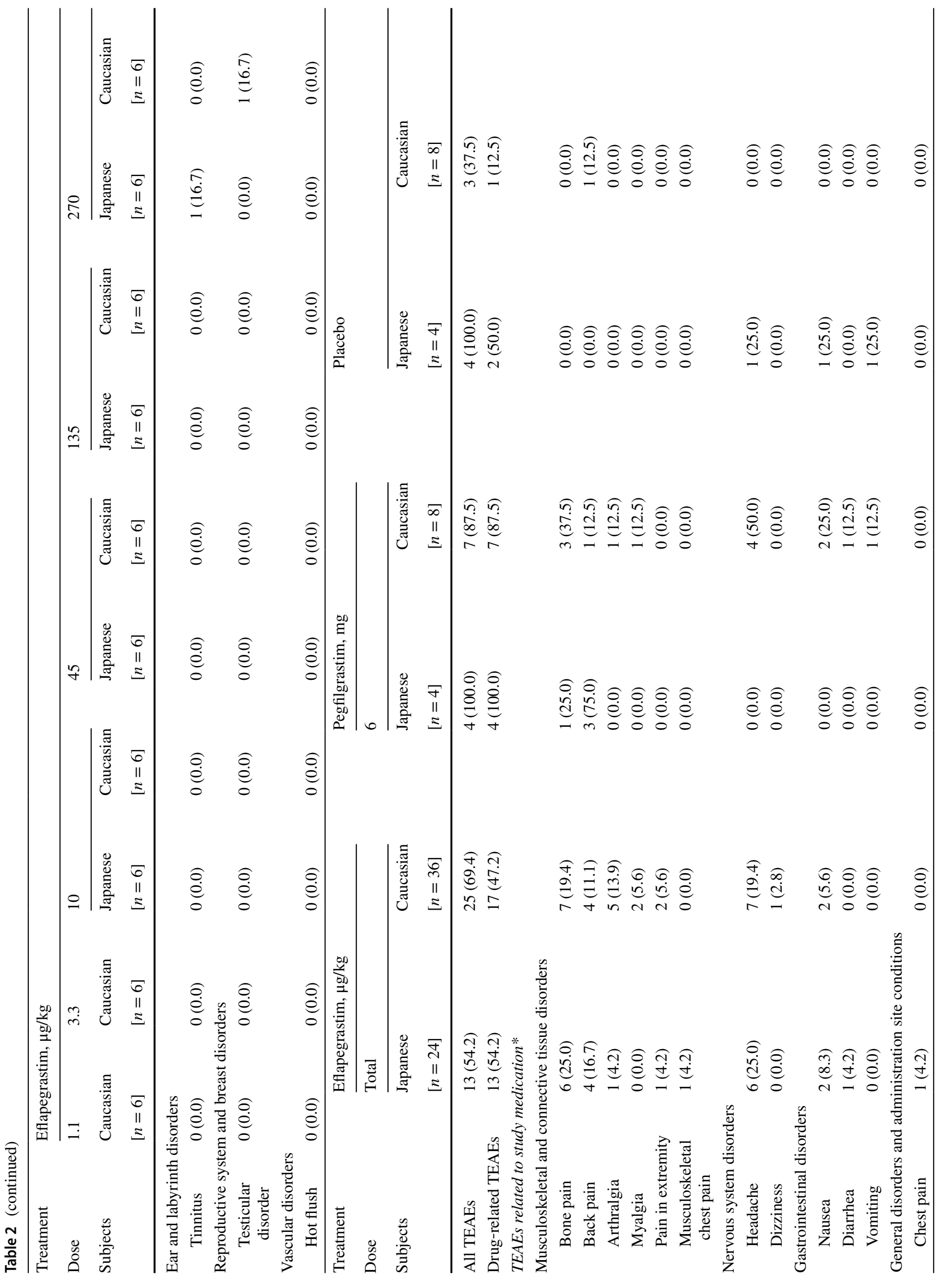




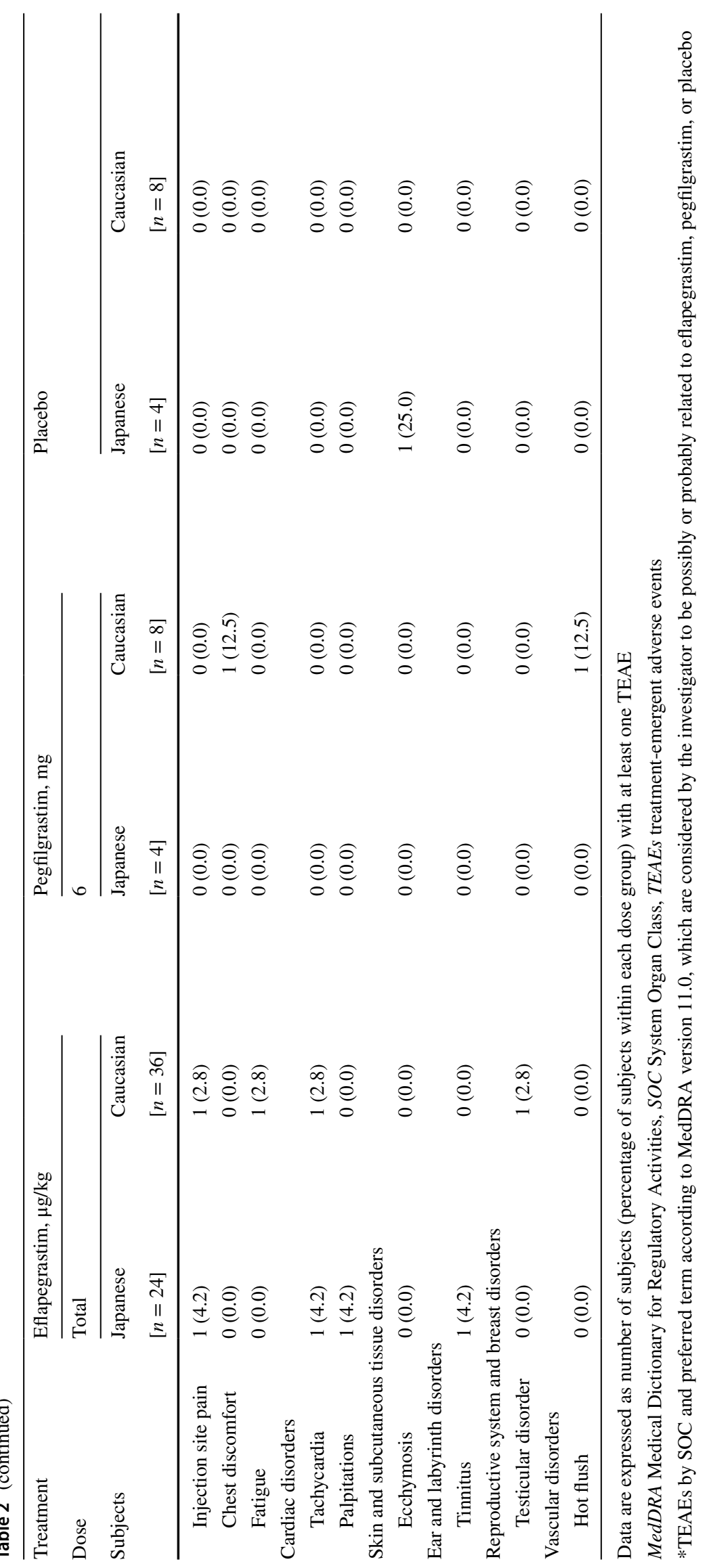




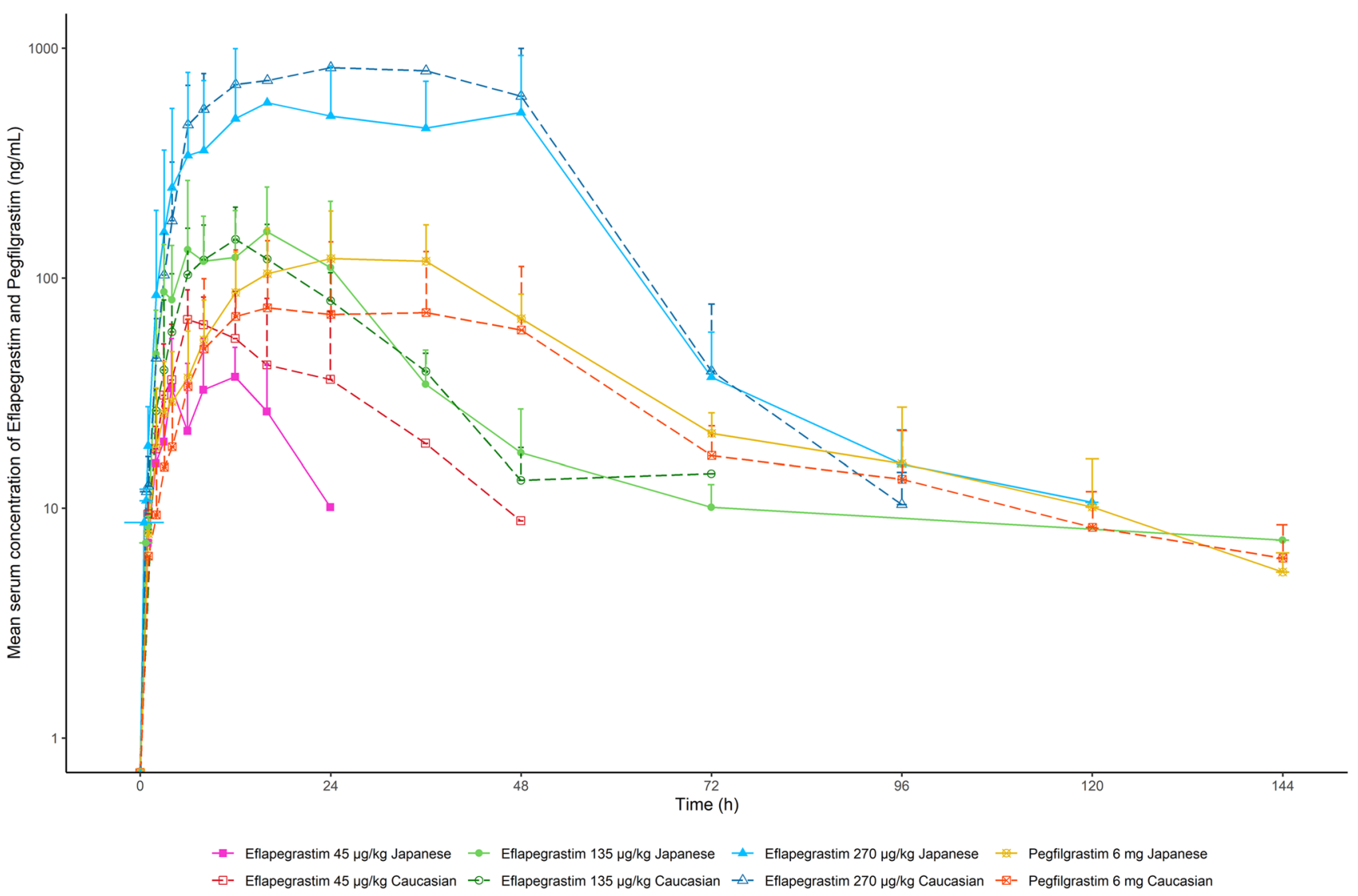

Fig. 2 Mean serum concentration-time profiles of eflapegrastim and pegfilgrastim after a single subcutaneous administration in Japanese and Caucasian subjects. Concentrations are shown in the log scale. The error bars represent the standard deviations

completed the study, with six withdrawals (4 and 1 Japanese subjects and 1 Caucasian subject, due to protocol violation, consent withdrawn, and travel abroad, respectively) (Fig. 1). The proportion of male and female subjects was equally balanced in each dose group (Table 1). The mean age, height, weight, and BMI were similar across the dose groups. The Japanese and Caucasian subjects had a mean (standard deviation [SD]) age of 29.3 (5.2) years and 29.8 (6.5), respectively (Table 1). Japanese subjects weighed lighter and had a lower BMI than Caucasian subjects, with a mean (SD) weight of $61.2(11.1)$ and $72.6(14.0) \mathrm{kg}$ and a mean (SD) BMI of $22.0(2.7)$ and $24.1(3.1) \mathrm{kg} / \mathrm{m}^{2}$, respectively $(p<0.005)$ (Table 1). Other baseline laboratory test results were in the normal range and were comparable between ethnic groups (Table 1).

\subsection{Safety, Tolerability, and Immunogenicity}

A single subcutaneous dose of eflapegrastim 1.1-270 $\mu \mathrm{g} /$ $\mathrm{kg}$ was safe and generally well tolerated in both Japanese and Caucasian subjects. No clinically significant abnormalities were observed in physical examination, laboratory tests, 12-lead ECG, or vital signs, except for one case of mild tachycardia reported in the $270 \mu \mathrm{g} / \mathrm{kg}$ eflapegrastim dose group. Likewise, no serious or severe AEs were seen. Most of the AEs were considered mild in intensity (seven AEs were moderate, data not shown) and all were resolved by the end of the study. A total of $56(66.7 \%)$ subjects reported one or more treatment-emergent AEs (TEAEs), of which 30,11 , and 3 were considered related to eflapegrastim, pegfilgrastim, and placebo, respectively (Table 2). The three higher doses of eflapegrastim (i.e., 45, 135, and $270 \mu \mathrm{g} / \mathrm{kg}$ ) and pegfilgrastim were associated with a greater frequency of TEAEs related to study medication than the three lower doses of eflapegrastim (i.e., 1.1, 3.3, and $10 \mu \mathrm{g} / \mathrm{kg}$ ) (Table 2). The most common TEAEs after eflapegrastim, particularly at the three higher doses, were bone pain, headache, and back pain, which were also frequently seen in the pegfilgrastim dose group. Overall, the safety profiles of eflapegrastim and pegfilgrastim were comparable between Japanese and Caucasian subjects (54.2 vs. $47.2 \%$, drug-related AEs) (Table 2). No subject was positive for the treatmentinduced formation of ADA. G-CSF neutralizing antibodies were also negative in all of the subjects. 
Table 3 Pharmacokinetic parameters of eflapegrastim and pegfilgrastim in Japanese and Caucasian subjects

\begin{tabular}{|c|c|c|c|c|c|c|c|c|}
\hline \multirow{3}{*}{$\begin{array}{l}\text { Treatment } \\
\text { Dose } \\
\text { Subjects }\end{array}$} & \multicolumn{6}{|c|}{ Eflapegrastim, $\mu \mathrm{g} / \mathrm{kg}$} & \multirow{2}{*}{\multicolumn{2}{|c|}{$\frac{\text { Pegfilgrastim, mg }}{6}$}} \\
\hline & \multicolumn{2}{|l|}{45} & \multicolumn{2}{|l|}{135} & \multicolumn{2}{|l|}{270} & & \\
\hline & $\begin{array}{l}\text { Japanese } \\
{[n=6]}\end{array}$ & $\begin{array}{l}\text { Caucasian } \\
{[n=6]}\end{array}$ & $\begin{array}{l}\text { Japanese } \\
{[n=6]}\end{array}$ & $\begin{array}{l}\text { Caucasian } \\
{[n=6]}\end{array}$ & $\begin{array}{l}\text { Japanese } \\
{[n=6]}\end{array}$ & $\begin{array}{l}\text { Caucasian } \\
{[n=6]}\end{array}$ & $\begin{array}{l}\text { Japanese } \\
{[n=4]}\end{array}$ & $\begin{array}{l}\text { Caucasian } \\
{[n=8]}\end{array}$ \\
\hline $\mathrm{C}_{\max }$ & $23.4 \pm 30.0^{\mathrm{a}}$ & $55.7 \pm 33.8^{\mathrm{a}}$ & $181.4 \pm 139.6$ & $152.5 \pm 47.8$ & $763.0 \pm 429.9$ & $989.8 \pm 280.6$ & $137.5 \pm 65.5$ & $84.2 \pm 70.6$ \\
\hline $\mathrm{T}_{\max }(\mathrm{h})$ & $6.0[4.0-8.0]^{\mathrm{a}}$ & $6.0[4.0-12.0]^{\mathrm{a}}$ & $8.0[4.0-16.0]$ & $12.0[12.0-24.0]$ & $26.0[12.0-48.0]$ & $30.0[6.0-36.0]$ & $30.0[16.0-36.0]$ & $30.0[12.0-48.0]$ \\
\hline $\begin{array}{l}\mathrm{AUC}_{\text {last }} \\
(\mu \mathrm{g} \bullet \mathrm{h} / \mathrm{L})\end{array}$ & $266.8 \pm 350.2^{\mathrm{a}}$ & $873.4 \pm 954.8^{\mathrm{a}}$ & $3415.5 \pm 2452.2$ & $3318.3 \pm 924.0$ & $25,822.5 \pm 16,785.5$ & $36,275.7 \pm 18908.6$ & $6185.8 \pm 1953.8$ & $4282.3 \pm 3172.0$ \\
\hline $\begin{array}{l}\mathrm{AUC}_{48} \\
(\mu \mathrm{g} \bullet \mathrm{h} / \mathrm{L})\end{array}$ & $893.9^{\mathrm{c}}$ & $1196.2 \pm 885.9^{\mathrm{b}}$ & $3930.0 \pm 1642.7^{\mathrm{a}}$ & $3502.7 \pm 881.5^{\mathrm{a}}$ & $21,168.8 \pm 13,567.5$ & $31,466.2 \pm 15455.0$ & $4315.5 \pm 1960.7$ & $2873.2 \pm 2681.5$ \\
\hline $\begin{array}{l}\mathrm{AUC}_{\infty} \\
(\mu \mathrm{g} \cdot \mathrm{h} / \mathrm{L})\end{array}$ & $895.8^{\mathrm{c}}$ & $1227.7 \pm 939.3^{\mathrm{b}}$ & $4429.1 \pm 2236.3^{\mathrm{a}}$ & $3831.3 \pm 527.5^{\mathrm{a}}$ & $27,128.6 \pm 18,411.1^{\mathrm{a}}$ & $39,974.6 \pm 20378.7^{\mathrm{a}}$ & $6643.5 \pm 2014.4$ & $4527.6 \pm 3221.9$ \\
\hline$t_{1 / 2}(h)$ & $5.25^{\mathrm{c}}$ & $6.7 \pm 1.6^{\mathrm{b}}$ & $20.4 \pm 22.3^{\mathrm{a}}$ & $12.9 \pm 8.7^{\mathrm{a}}$ & $19.1 \pm 14.6^{\mathrm{a}}$ & $16.6 \pm 11.0^{\mathrm{a}}$ & $33.6 \pm 7.9$ & $27.1 \pm 9.2$ \\
\hline $\begin{array}{l}\mathrm{CL}(\mathrm{L} / \mathrm{h} / \\
\mathrm{kg})\end{array}$ & $0.050^{\mathrm{c}}$ & $0.050 \pm 0.024^{\mathrm{b}}$ & $0.037 \pm 0.018^{\mathrm{a}}$ & $0.036 \pm 0.005^{\mathrm{a}}$ & $0.023 \pm 0.031^{\mathrm{a}}$ & $0.012 \pm 0.015^{\mathrm{a}}$ & $0.014 \pm 0.006^{\mathrm{d}}$ & $0.028 \pm 0.020^{\mathrm{d}}$ \\
\hline
\end{tabular}

Data are expressed as arithmetic mean \pm standard deviation, except for $T_{\max }$, which is expressed as median (minimum-maximum) ${ }^{a}$ Because of the limited number of samples available for the eflapegrastim profile, data were only estimable for five of six subjects ${ }^{b}$ Because of the limited number of samples available for the eflapegrastim profile, data were only estimable for four of six subjects ${ }^{\mathrm{c}}$ Because of the limited number of samples available for the eflapegrastim profile, data were only estimable for one of six subjects ${ }^{\mathrm{d}} \mathrm{CL}$ normalized based on $70 \mathrm{~kg}$ adult body weight

$A U C_{\text {last }}$ area under the serum concentration-time curve from time zero to the last observed concentration, $A U C_{48}$ area under the serum concentration-time curve from time zero to $48 \mathrm{~h}, A U C_{\infty}$ area under the serum concentration-time curve from time zero to the infinity, $C_{m a x}$ maximum serum concentration at steady state, $C L$ total serum clearance, $t_{1 / 2}$ terminal elimination half-life, $T_{\max }$ time to reach the maximum serum concentration

\subsection{Pharmacokinetics}

Reliable serum concentrations, over the range of 3.13-200 $\mathrm{ng} / \mathrm{mL}$, were obtained in the three higher eflapegrastim dose groups (i.e., 45,135 , and $270 \mu \mathrm{g} / \mathrm{kg}$ ), while most of the concentrations in the three lower eflapegrastim dose groups (i.e., $1.1,3.3$, and $10 \mu \mathrm{g} / \mathrm{kg}$ ) were below the LLOQ. Therefore, PK assessments were performed in the 45, 135, and $270 \mu \mathrm{g} /$ $\mathrm{kg}$ dose groups.

After a single subcutaneous administration, eflapegrastim was slowly but steadily absorbed, reaching the peak concentration at $6-30 \mathrm{~h}$ postdose (Fig. 2, Table 3). Eflapegrastim was eliminated following a mono-exponential decrease pattern up to $24 \mathrm{~h}$ postdose in the $45 \mu \mathrm{g} / \mathrm{kg}$ dose group, with a $t_{1 / 2}$ of 5-7 h, whereas a bi-exponential decline up to $144 \mathrm{~h}$ postdose was more apparent in the 135 and $270 \mu \mathrm{g} /$ $\mathrm{kg}$ dose groups, with a $t_{1 / 2}$ of $13-20 \mathrm{~h}$ (Fig. 2). The $C_{\max }$ of eflapegrastim increased dose proportionally over a range of $45-270 \mu \mathrm{g} / \mathrm{kg}$, i.e., the estimated slope in the power model was close to $1(0.90,95 \%$ CI $0.64-1.17)$. Likewise, the AUC last of eflapegrastim increased in a dose-proportional manner $(0.84,95 \%$ CI $0.39-1.29)$, whereas AUC $_{\infty}$ showed a dosedependent increase slightly more than proportional (1.67, 95\% CI 1.17-2.17). Pegfilgrastim $6 \mathrm{mg}$ after a single subcutaneous administration reached the peak concentration at $30 \mathrm{~h}$ postdose and was eliminated, with a $t_{1 / 2}$ of $30 \mathrm{~h}$ (Fig. 2,
Table 3). Overall, serum concentration-time profiles and PK parameters of eflapegrastim and pegfilgrastim were comparable between Japanese and Caucasian subjects across dose groups (Fig. 2, Table 3).

\subsection{Pharmacodynamics}

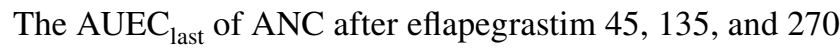
$\mu \mathrm{g} / \mathrm{kg}$ showed a clear dose-dependent effect. The mean ANC-time profiles of eflapegrastim 45, 135, and $270 \mu \mathrm{g} / \mathrm{kg}$ and pegfilgrastim $6 \mathrm{mg}$ in Japanese and Caucasian subjects are presented (Fig. 3). The median time to reach $\mathrm{ANC}_{\max }$ of eflapegrastim 45,135 , and $270 \mu \mathrm{g} / \mathrm{kg}$ was $20.0,48.0$, and $74.2 \mathrm{~h}$ in Japanese subjects and $36.0,42.1$, and $74.0 \mathrm{~h}$ in Caucasian subjects, respectively (Table 4). The AUEC last of ANC and $\mathrm{ANC}_{\text {max }}$ of eflapegrastim increased as the dose increased in both ethnic groups (Table 4). The increase in ANC by eflapegrastim 45 and $135 \mu \mathrm{g} / \mathrm{kg}$ was similar between Japanese and Caucasian subjects, with the greater increase shown in Caucasian subjects at a dose of $270 \mu \mathrm{g} /$ $\mathrm{kg}$ (Fig. 3, Table 4). The median time to reach the $\mathrm{ANC}_{\max }$ of pegfilgrastim $6 \mathrm{mg}$ was 73.5 and $48.0 \mathrm{~h}$ in Japanese and Caucasian subjects, respectively (Table 4). The increase in ANC by pegfilgrastim $6 \mathrm{mg}$ was greater in Japanese subjects compared with Caucasian subjects (Fig. 3, Table 4). 


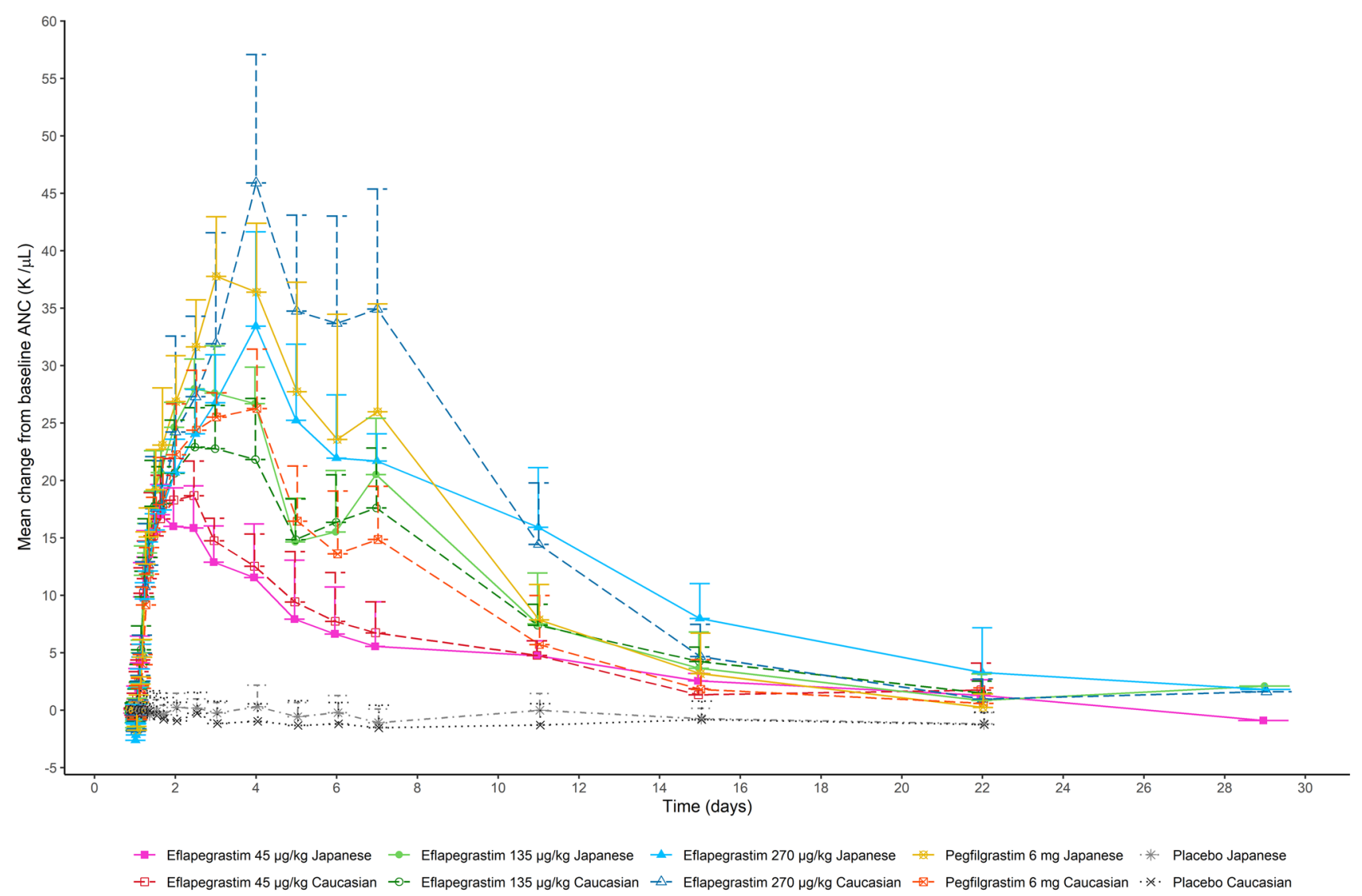

Fig. 3 Mean change from baseline in absolute neutrophil count over time after a single subcutaneous administration of eflapegrastim and pegfilgrastim in Japanese and Caucasian subjects. Baseline was the

Similar to ANC, the $\mathrm{AUEC}_{\text {last }}$ of CD34 ${ }^{+}$cell count after eflapegrastim 45,135 , and $270 \mu \mathrm{g} / \mathrm{kg}$ showed a clear dose-dependent effect. The mean $\mathrm{CD} 34^{+}$cell count-time profiles of eflapegrastim 45,135 , and $270 \mu \mathrm{g} / \mathrm{kg}$ and pegfilgrastim $6 \mathrm{mg}$ in Japanese and Caucasian subjects are presented (Fig. 4). The median time to reach the $\mathrm{CD} 34^{+}{ }_{\text {max }}$ of eflapegrastim $45-270 \mu \mathrm{g} / \mathrm{kg}$ was $74.7-97.6 \mathrm{~h}$ in Japanese subjects and 97.4-98.1 h in Caucasian subjects (Table 4). The $\mathrm{AUEC}_{\text {last }}$ of CD34+ cell count and CD34 ${ }^{+}$max of eflapegrastim increased as the dose increased in both ethnic groups (Fig. 4). The increase in $\mathrm{CD} 34^{+}$cell count by eflapegrastim 45 and $135 \mu \mathrm{g} / \mathrm{kg}$ was similar between Japanese and Caucasian subjects, with the greater increase shown in Caucasian subjects at a dose of $270 \mu \mathrm{g} / \mathrm{kg}$ (Fig. 4, Table 4). The median time to reach the $\mathrm{CD} 34^{+}{ }_{\text {max }}$ of pegfilgrastim $6 \mathrm{mg}$ was 98.2 and $97.8 \mathrm{~h}$ in Japanese and Caucasian subjects, respectively (Table 4). The increase in $\mathrm{CD} 34^{+}$cell count by pegfilgrastim $6 \mathrm{mg}$ was greater in Caucasian subjects compared with Japanese subjects (Fig. 4, Table 4).

The systemic exposure to eflapegrastim, as assessed by $\mathrm{AUC}_{\text {last }}$, was significantly associated with $\mathrm{AUEC}_{\text {last }}$ of both last nonmissing assessment prior to dosing. The error bars denote the standard deviations. ANC absolute neutrophil count

ANC and CD34 ${ }^{+}$cell count in Japanese and Caucasian subjects $(p<0.005)$ [Fig. 5].

\section{Discussion}

In this phase I study, a single subcutaneous dose of eflapegrastim (Rolontis ${ }^{\circledR}$ ) $1.1-270 \mu \mathrm{g} / \mathrm{kg}$ was safe and well tolerated in healthy Japanese and Caucasian subjects. In both ethnic groups, eflapegrastim $45-135 \mu \mathrm{g} / \mathrm{kg}$ showed a dosedependent increase in ANC and CD34 ${ }^{+}$cell count.

All TEAEs after eflapegrastim were transient and had recovered spontaneously or with medication for TEAEs without any eflapegrastim-related TEAEs, leading to study discontinuation. The most frequent drug-related TEAEs (in $\geq 20 \%$ of patients) in the eflapegrastim groups included bone pain and headache, commonly observed in previous studies with other G-CSF treatments such as filgrastim and pegfilgrastim [10, 15-19]. No clinically significant abnormalities were noted after eflapegrastim administration in the physical examination, laboratory tests, 12-lead ECG, vital signs, or local tolerability. No neutralizing antibodies against 


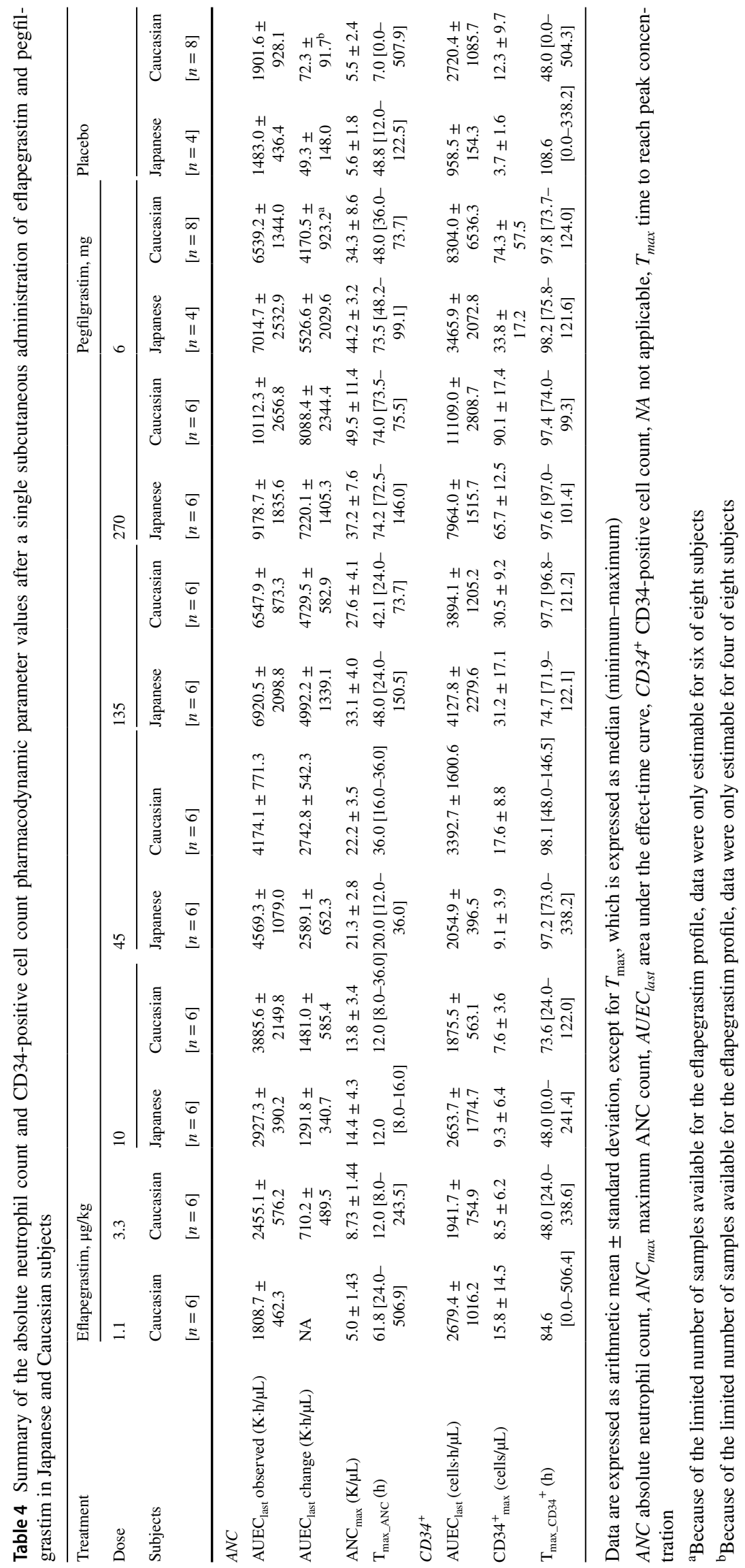




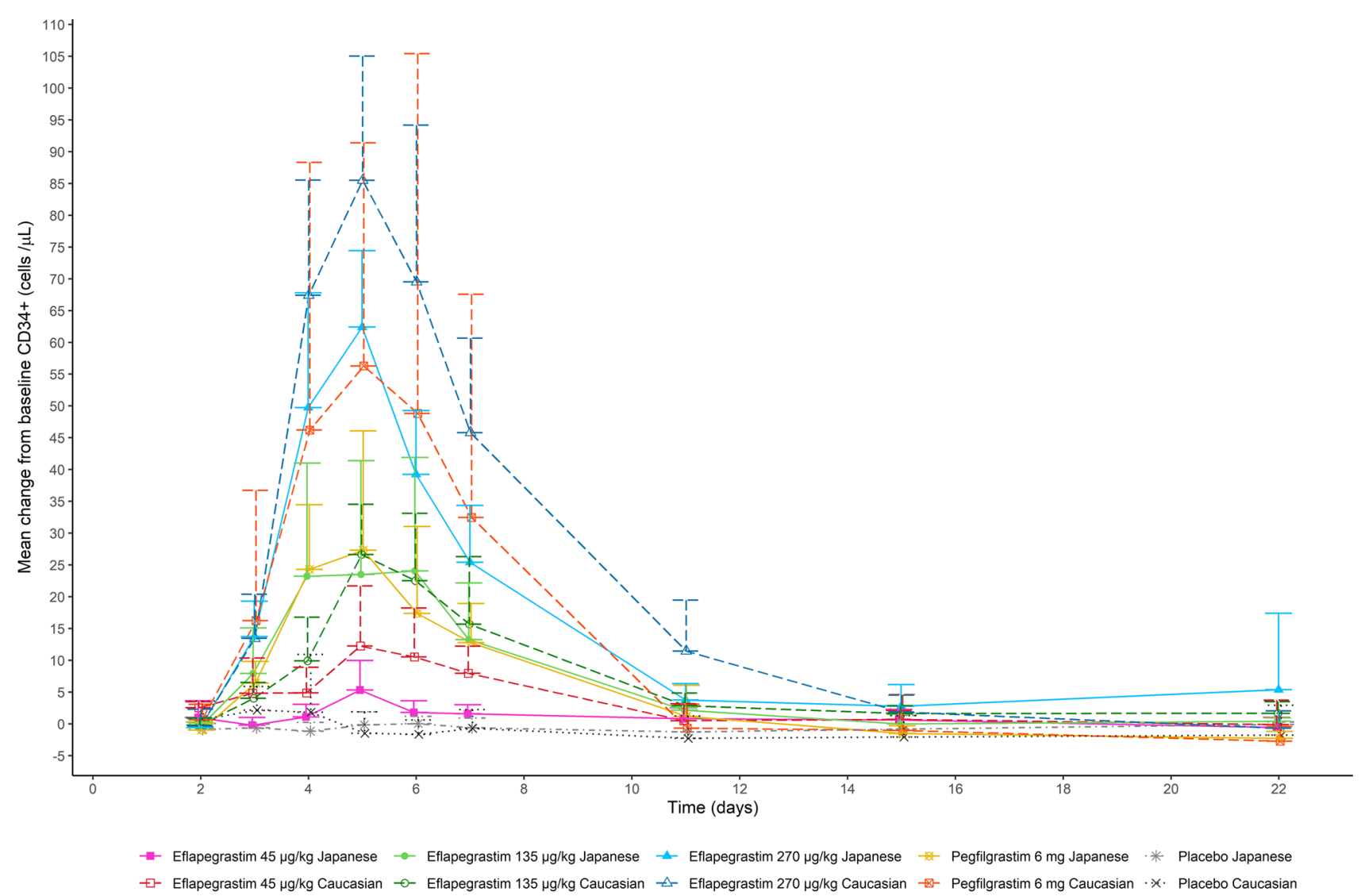

Fig. 4 Mean change from baseline in CD34-positive cell count over time after a single subcutaneous administration of eflapegrastim and pegfilgrastim in Japanese and Caucasian subjects. Baseline was the

eflapegrastim or G-CSF were detected in either Japanese or Caucasian subjects. The presence of ADA for eflapegrastim was similar to observations from previous studies with pegfilgrastim [20-22].

The exposure to eflapegrastim increased in a greater than dose-proportional manner, most likely because the clearance was decreased as the dose was increased [10]. The nonlinear PK of eflapegrastim shown in the present study were consistent with those previously reported for G-CSF PK characteristics [23-25], which were attributed to the saturated receptor binding on neutrophils. The primary elimination pathways for G-CSF are renal clearance and neutrophilmediated clearance. While filgrastim is primarily eliminated via both renal and neutrophil-mediated pathways, pegylation of filgrastim makes the molecule too large to be renally eliminated, leaving neutrophil-mediated clearance dominant $[26,27]$. The Fc fragment of eflapegrastim may also render renal clearance negligible.

Eflapegrastim serum concentrations were maintained until the production of neutrophils and neutrophil precursors increased, at which point they began to decline rapidly as ANC recovered, consistent with a neutrophil-mediated last nonmissing assessment prior to dosing. The error bars denote the standard deviations. $C D 34^{+} \mathrm{CD} 34$-positive cell count

clearance mechanism. In addition, because the clearance of eflapegrastim is self-regulated by neutrophils, which changes according to the neutrophil recovery, a single dose of eflapegrastim or pegfilgrastim is needed once per chemotherapy cycle in contrast to daily injections required for filgrastim.

Overall, the safety profile was similar between eflapegrastim and pegfilgrastim. The most common AE associated with G-CSF administration was bone pain [16-19], particularly after eflapegrastim $135-270 \mu \mathrm{g} / \mathrm{kg}(n=10$, $41.6 \%$ ), while it was reported to be lower for pegfilgrastim $6 \mathrm{mg}(n=4,33.3 \%)$ [Table 2]. The increase in ANC and CD $34^{+}$cell count after eflapegrastim $135-270 \mu \mathrm{g} / \mathrm{kg}$ was also comparable with that after pegfilgrastim $6 \mathrm{mg}$ (Figs. 3 and 4). The exposure to eflapegrastim $135 \mu \mathrm{g} / \mathrm{kg}$ was similar or slightly lower than that of pegfilgrastim $6 \mathrm{mg}$, yet eflapegrastim $135 \mu \mathrm{g} / \mathrm{kg}$ reached the peak concentration faster than pegfilgrastim $6 \mathrm{mg}$ ( $8-12$ h vs. $30 \mathrm{~h}$ ) (Table 3). Collectively, eflapegrastim 135-270 $\mu \mathrm{g} / \mathrm{kg}$ and pegfilgrastim $6 \mathrm{mg}$ exerted comparable PK and PD effects.

One strength of this study was the investigation of ethnic sensitivity for eflapegrastim between Japanese and Caucasian subjects. The safety and tolerability profiles of 


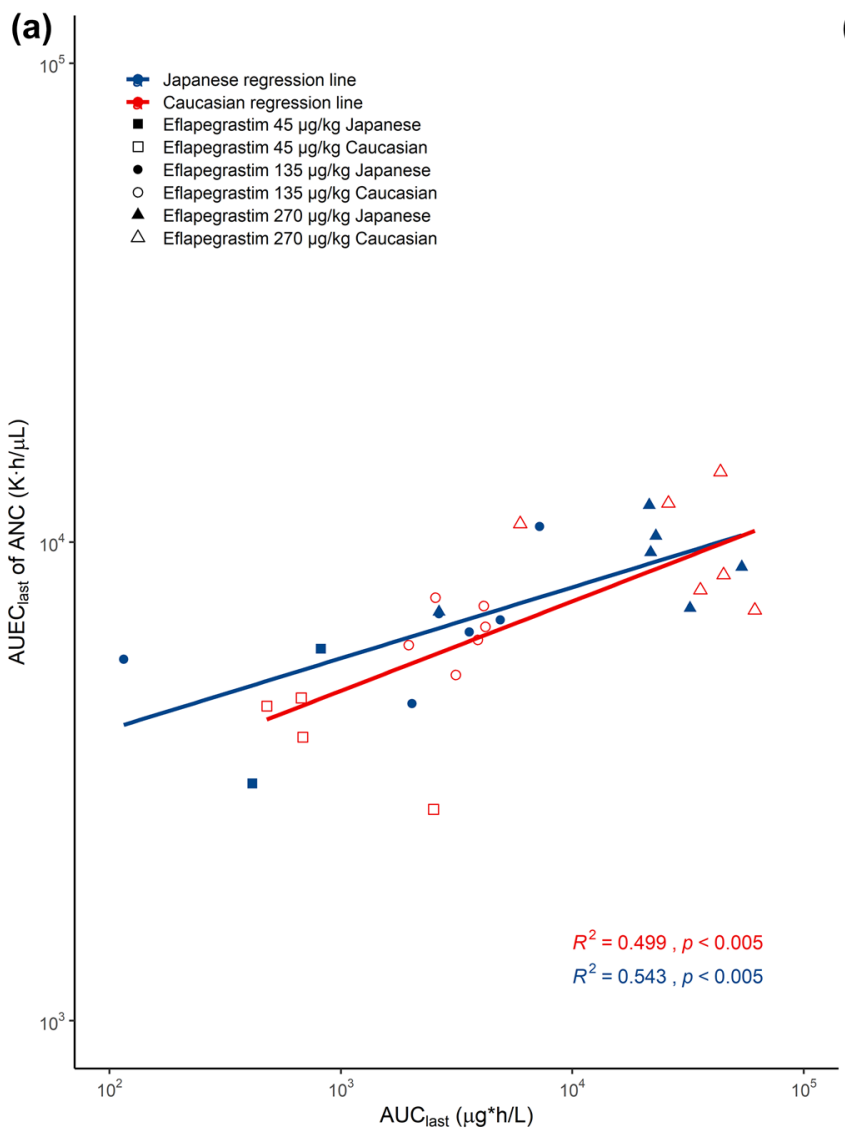

Fig. 5 Pharmacokinetic and pharmacodynamic relationship of eflapegrastim: a $\ln \left(\mathrm{AUC}_{\text {last }}\right)$ vs. $\ln \left(\mathrm{AUEC}_{\text {last }}\right.$ of $\left.\mathrm{ANC}\right)$ and $\mathbf{b} \ln \left(\mathrm{AUC}_{\text {last }}\right)$ vs. ln $\left(\mathrm{AUEC}_{\text {last }}\right.$ of $\left.\mathrm{CD}^{2} 4^{+}\right) . A N C$ absolute neutrophil count, $A U C_{\text {last }}$ area

eflapegrastim were comparable between Japanese and Caucasian subjects. Similarly, no significant ethnic difference was observed in the PK/PD profiles of eflapegrastim. The exposure level at $270 \mu \mathrm{g} / \mathrm{kg}$ eflapegrastim with ANC or $\mathrm{CD} 34^{+}$cell count tended to be slightly higher in Caucasian subjects than in Japanese subjects (Figs. 2, 3, 4); however, the small number of subjects enrolled in each ethnic group $(n=6)$ may have contributed to this discrepancy in eflapegrastim dose responses.

Another phase I study evaluated the PK and PD profiles of a single subcutaneous administration of eflapegrastim 5, $15,45,135$, or $350 \mu \mathrm{g} / \mathrm{kg}$ in healthy Koreans [10]. Comparable PK and PD profiles were noted between Japanese and Caucasian subjects in the present study and Korean subjects in the other study. In particular, AUEC ${ }_{\text {last }}$ of ANC in Koreans after eflapegrastim $135 \mathrm{ug} / \mathrm{kg}$ was $6230.2 \mathrm{~K} \cdot \mathrm{h} / \mu \mathrm{L}$ [10], comparable with 6920.5 and $6547.9 \mathrm{~K} \cdot \mathrm{h} / \mu \mathrm{L}$ seen in Japanese and Caucasian subjects in the present study. The lack of ethnic differences in the PK/PD profiles of eflapegrastim may suggest no dose adjustment is required for different ethnic groups. Ethnic sensitivity assessment among these three ethnic groups is ongoing for the dose justification as published

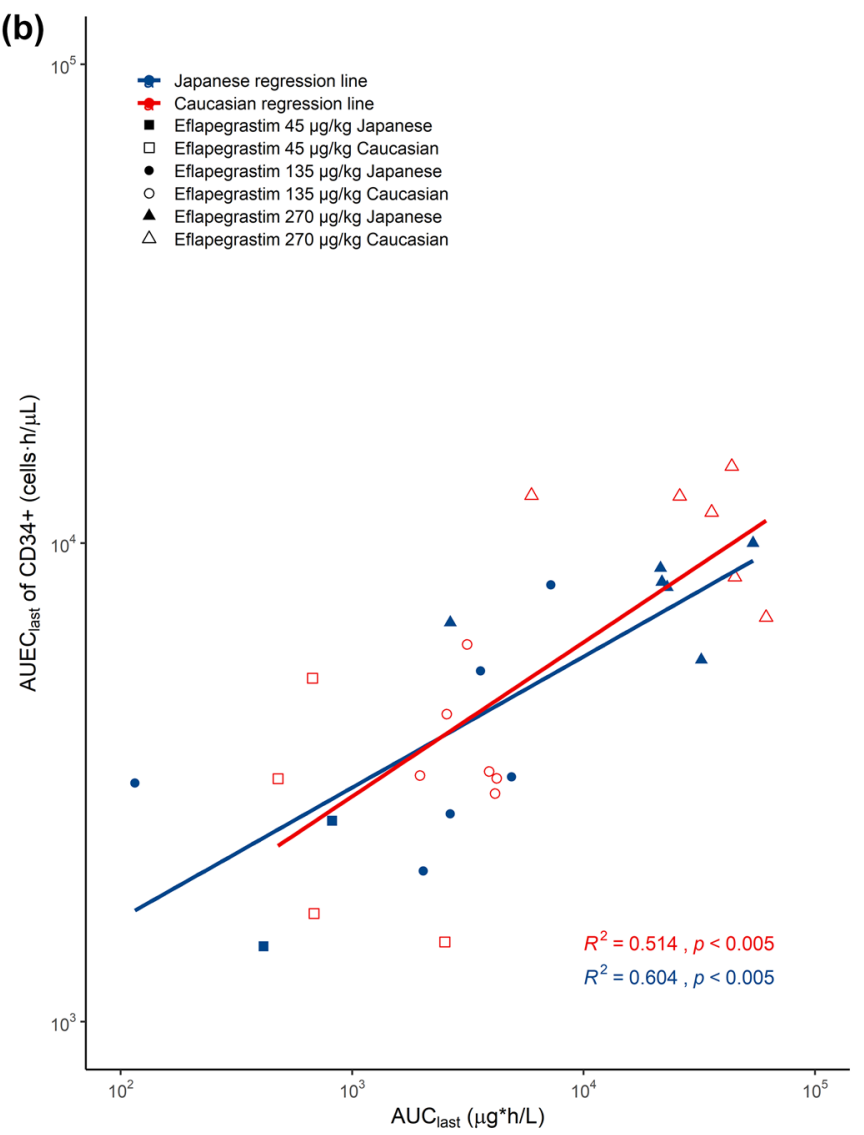

under the serum concentration-time curve from time zero to the last observed concentration, $A U E C_{\text {last }}$ area under the effect-time curve, $C D 34^{+} \mathrm{CD} 34$-positive cell count

in the ICH E5 (Ethnic Factors in the Acceptance of Foreign Clinical Data); evaluation of diverse ethnic groups, particularly in the early phase of drug development, is critical to a global drug development program.

This study had several limitations. First, the study was performed in healthy subjects. The effect of eflapegrastim to prevent chemotherapy-induced neutropenia can be more accurately evaluated in cancer patients. However, given the mechanism of G-CSF, the increase in ANC and CD34 ${ }^{+}$cell count by eflapegrastim seen in the present study with healthy subjects is likely to be repeated in cancer patients suffering from chemotherapy-induced febrile neutropenia. Second, we enrolled only a small number of subjects in each dose group, given the exploratory nature of this phase I clinical study. However, further phase II [28] and phase III studies with eflapegrastim, i.e., ADVANCE [29] and RECOVER [11], investigated the efficacy and safety of eflapegrastim in patients with early-stage breast cancer for the prevention of chemotherapy-induced neutropenia. 


\section{Conclusion}

Eflapegrastim (Rolontis ${ }^{\circledR}$ ), a novel long-acting G-CSF, was safe and well tolerated after a single subcutaneous administration at $1.1-270 \mu \mathrm{g} / \mathrm{kg}$ in healthy Japanese and Caucasian subjects. In both ethnic groups, eflapegrastim showed dosedependent $\mathrm{PK}$ and the systemic exposure to eflapegrastim was positively correlated with $\mathrm{ANC}$ and $\mathrm{CD} 34^{+}$cell count. The PK/PD profiles were comparable between Japanese and Caucasian subjects administered eflapegrastim 45-135 $\mu \mathrm{g} /$ $\mathrm{kg}$, suggesting that different dosage regimens based on ethnicity are unlikely required for eflapegrastim, at least up to $135 \mu \mathrm{g} / \mathrm{kg}$. The ethnicity sensitivity assessment of eflapegrastim among Korean, Japanese, and Caucasian subjects is in progress to further justify the dose adjustment of eflapegrastim for various ethnic groups.

Acknowledgements The authors thank all volunteers and investigators/ study site staff who participated in this study.

\section{Declarations}

Funding This study was sponsored by Hanmi Pharmaceutical Co., Ltd., (Protocol No. 08-HM10460A-101) Seoul, South Korea.

Conflict of interest NL, SB, and JDC are employees of Hanmi Pharmaceutical Co., Ltd. YJ and HL have no conflicts of interest to declare that are relevant to the contents of this article. SJ received funding from Hanmi Pharmaceutical Co., Ltd. to conduct this study.

Availability of data and material The datasets generated and/or analyzed are available from the corresponding author upon reasonable request.

Code availability Not applicable.

Author contributions $\mathrm{YJ}$ and NL participated equally in the analysis and interpretation of data and wrote the manuscript. HL, SB, and JDC contributed to the analysis and interpretation of data. SJ contributed to the conception and design of the study, and the acquisition, analysis and interpretation of data. All authors reviewed and provided comments on the manuscript, and all authors read and approved the final manuscript.

Ethics approval This study was conducted in accordance with the Declaration of Helsinki, the International Council for Harmonization Good Clinical Practice guidelines, and in compliance with local regulatory requirements. The study protocol was reviewed and approved by the Institutional Review Board (Aspire IRB).

Consent to participate All participants provided written informed consent before they underwent screening for eligibility.

Consent for publication All participants provided written informed consent for their data to be published.

Open Access This article is licensed under a Creative Commons Attribution-NonCommercial 4.0 International License, which permits any non-commercial use, sharing, adaptation, distribution and reproduction in any medium or format, as long as you give appropriate credit to the original author(s) and the source, provide a link to the Creative
Commons licence, and indicate if changes were made. The images or other third party material in this article are included in the article's Creative Commons licence, unless indicated otherwise in a credit line to the material. If material is not included in the article's Creative Commons licence and your intended use is not permitted by statutory regulation or exceeds the permitted use, you will need to obtain permission directly from the copyright holder. To view a copy of this licence, visit http://creativecommons.org/licenses/by-nc/4.0/.

\section{References}

1. Caggiano V, Weiss RV, Rickert TS, Linde-Zwirble WT. Incidence, cost, and mortality of neutropenia hospitalization associated with chemotherapy. Cancer. 2005;103:1916-24.

2. Mehta HM, Malandra M, Corey SJ. G-CSF and GM-CSF in neutropenia. J Immunol. 2015;195:1341-9.

3. Filgrastim. The American Society of Health-System Pharmacist. https://www.drugs.com/monograph/filgrastim.html. Accessed 23 Jul 2021.

4. Panopoulos AD, Watowich SS. Granulocyte colony-stimulating factor: molecular mechanisms of action during steady state and 'emergency' hematopoiesis. Cytokine. 2008;42:277-88.

5. Kuwabara T, Kobayashi S, Sugiyama Y. Pharmacokinetics and pharmacodynamics of a recombinant human granulocyte colonystimulating factor. Drug Metab Rev. 1996;28:625-58.

6. Ballestrero A, Boy D, Gonella R, Miglino M, Clavio M, Barbero $\mathrm{V}$, et al. Pegfilgrastim compared with filgrastim after autologous peripheral blood stem cell transplantation in patients with solid tumours and lymphomas. Ann Hematol. 2008;87:49-55.

7. Becker PS, Griffiths EA, Alwan LM, Bachiashvili K, Brown A, Cool R, et al. NCCN Guidelines Insights: Hematopoietic Growth Factors, Version 1.2020. J Natl Compr Cancer Netw. 2020;18:12-22.

8. Smith TJ, Bohlke K, Lyman GH, Carson KR, Crawford J, Cross SJ, et al. Recommendations for the Use of WBC Growth Factors: American Society of Clinical Oncology Clinical Practice Guideline Update. J Clin Oncol. 2015;33:3199-212.

9. Weycker D, Wu H, Hagiwara M, Li X, Barron RL. Use of chemotherapy and same-day pegfilgrastim prophylaxis in US clinical practice. Blood. 2014;124:4825.

10. Shin KH, Kim TE, Lim KS, Yoon SH, Cho JY, Kim SE, et al. Pharmacokinetic and pharmacodynamic properties of a new long-acting granulocyte colony-stimulating factor (HM10460A) in healthy volunteers. BioDrugs. 2013;27:149-58.

11. Cobb PW, Moon YW, Mezei K, Láng I, Bhat G, Chawla S, et al. A comparison of eflapegrastim to pegfilgrastim in the management of chemotherapy-induced neutropenia in patients with early-stage breast cancer undergoing cytotoxic chemotherapy (RECOVER): a phase 3 study. Cancer Med. 2020;9:6234-43.

12. Barrett JA, Choi J, Lakshmikanthan S, Kim Y-Y, Greene D, Kolli $\mathrm{P}$, et al. Eflapegrastim's enhancement of efficacy compared with pegfilgrastim in neutropenic rats supports potential for same-day dosing. Exp Hematol. 2020;92:51-61.

13. Kim YH, Choi I, Kolli P, Reddy G. Abstract 1347: in vivo efficacy of eflapegrastim in rats with chemotherapy-induced neutropenia. Can Res. 2017;77:1347.

14. Hauschke D. Bioequivalence and statistics in clinical pharmacology. Biometrics. 2006;62:945-6.

15. NEULASTA ${ }^{\circledR}$ (Pegfilgrastim) Injection, for Subcutaneous Use Prescribing Information. Amgen Inc.; 2021. https://www.pi. amgen.com/ /media/amgen/repositorysites/pi-amgen-com/neula sta/neulasta_pi_hcp_english.pdf. Accessed 27 May 2021.

16. Abboud CN, Lang N, Fung H, Lammerich A, Buchner A, Liu P, et al. Real-world safety experience of tevagrastim/ratiograstim/ 
biograstim and tbo-filgrastim, short-acting recombinant human granulocyte colony-stimulating factors. Support Care Cancer. 2019;27:2569-77.

17. Lambertini M, Del Mastro L, Bellodi A, Pronzato P. The five "Ws" for bone pain due to the administration of granulocytecolony stimulating factors (G-CSFs). Crit Rev Oncol Hematol. 2014;89:112-28.

18. Tigue CC, Mckoy JM, Evens AM, Trifilio SM, Tallman MS, Bennett CL. Granulocyte-colony stimulating factor administration to healthy individuals and persons with chronic neutropenia or cancer: an overview of safety considerations from the Research on Adverse Drug Events and Reports project. Bone Marrow Transplant. 2007;40:185-92.

19. Stroncek D, Clay M, Petzoldt M, Smith J, Jaszcz W, Oldham F, et al. Treatment of normal individuals with granulocyte-colonystimulating factor: donor experiences and the effects on peripheral blood CD34+ cell counts and on the collection of peripheral blood stem cells. Transfusion. 1996;36:601-10.

20. Green MD, Koelbl H, Baselga J, Galid A, Guillem V, Gascon $\mathrm{P}$, et al. A randomized double-blind multicenter phase III study of fixed-dose single-administration pegfilgrastim versus daily filgrastim in patients receiving myelosuppressive chemotherapy. Ann Oncol. 2003;14:29-35.

21. Holmes FA, Jones SE, O'Shaughnessy J, Vukelja S, George T, Savin M, et al. Comparable efficacy and safety profiles of onceper-cycle pegfilgrastim and daily injection filgrastim in chemotherapy-induced neutropenia: a multicenter dose-finding study in women with breast cancer. Ann Oncol. 2002;13:903-9.

22. Holmes FA, O'Shaughnessy JA, Vukelja S, Jones SE, Shogan J, Savin M, et al. Blinded, randomized, multicenter study to evaluate single administration pegfilgrastim once per cycle versus daily filgrastim as an adjunct to chemotherapy in patients with high-risk stage II or stage III/IV breast cancer. J Clin Oncol. 2002;20:727-31.

23. van der Auwera P, Platzer E, Xu Z-X, Schulz R, Feugeas O, Capdeville R, et al. Pharmacodynamics and pharmacokinetics of single doses of subcutaneous pegylated human G-CSF mutant (Ro 25-8315) in healthy volunteers: Comparison with single and multiple daily doses of filgrastim. Am J Hematol. 2001;66:245-51.

24. Johnston E, Crawford J, Blackwell S, Bjurstrom T, Lockbaum P, Roskos L, et al. Randomized, dose-escalation study of SD/01 compared with daily filgrastim in patients receiving chemotherapy. J Clin Oncol. 2000;18:2522-8.

25. Molineux G, Kinstler O, Briddell B, Hartley C, McElroy P, Kerzic $\mathrm{P}$, et al. A new form of Filgrastim with sustained duration in vivo and enhanced ability to mobilize PBPC in both mice and humans. Exp Hematol. 1999;27:1724-34.

26. Roskos L, Yank B, Schwab G, Lockbaum P, Molineux G, Johnston E, et al. Cytokinetic model of rmethHuG-CSF-SD/01 (SD/01) mediated granulopoiesis and the 'self-regulation' of SD/01 elimination in non-small cell lung cancer. Blood. 1998;92:507A.

27. Yang B, Kido A, Salfi M, Swan S, Sullivan JT. Pharmacokinetics and pharmacodynamics of pegfilgrastim in subjects with various degrees of renal function. J Clin Pharmacol. 2008;48:1025-31.

28. Vacirca JL, Chan A, Mezei K, Adoo CS, Pápai Z, Mcgregor K, et al. An open-label, dose-ranging study of Rolontis, a novel long-acting myeloid growth factor, in breast cancer. Cancer Med. 2018;7:1660-9.

29. Schwartzberg LS, Bhat G, Peguero J, Agajanian R, Bharadwaj JS, Restrepo A, et al. Eflapegrastim, a long-acting granulocytecolony stimulating factor for the management of chemotherapyinduced neutropenia: results of a phase III trial. Oncologist. 2020;25(8):e1233-41.

\section{Authors and Affiliations}

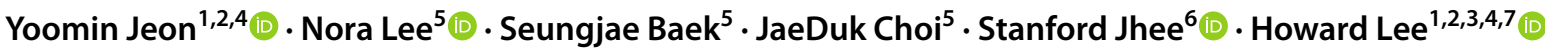

1 Department of Applied Biomedical Engineering, Graduate School of Convergence Science and Technology, Seoul National University, Seoul 08826, South Korea

2 Department of Molecular Medicine and Biopharmaceutical Sciences, Graduate School of Convergence Science and Technology, Seoul National University, Seoul 08826, South Korea

3 Department of Clinical Pharmacology and Therapeutics, Seoul National University College of Medicine and Hospital, Seoul 03080, South Korea
4 Center for Convergence Approaches in Drug Development, Graduate School of Convergence Science and Technology, Seoul National University, Seoul 08826, South Korea

5 Hanmi Pharmaceutical Co., Ltd., Seoul 05545, South Korea

6 Parexel International, Glendale, CA 91206, USA

7 Advanced Institute of Convergence Technology, Gyeonggi-do 16229, South Korea 